Article

\title{
Experimental Investigations on the Influence of Coil Arrangement on Melting/Solidification Processes
}

\author{
R. Andrzejczyk *, P. Kozak and T. Muszyński
}

Faculty of Mechanical Engineering, Gdansk University of Technology, Narutowicza 11/12, 80-233 Gdansk, Poland; przkozak@pg.edu.pl (P.K.); tomasz.muszynski@pg.edu.pl (T.M.)

* Correspondence: rafal.andrzejczyk@pg.edu.pl

Received: 9 October 2020; Accepted: 24 November 2020; Published: 1 December 2020

\begin{abstract}
The latent heat thermal energy storage units are very popular because of their high energy density and almost close to constant temperature during the charging/discharging. In the present study has been proposed new shell-and-coil geometry with a shifted coil position to enhance the performance of phase change thermal magazine. The experimental investigations have been performed both for the melting and solidification process of coconut oil for constant wall temperature conditions. The experiments have been carried out for cylindrical as well as coil shape geometry of the TES unit. In the case of annular TES, the copper tube with outer diameter $\mathrm{d}=10 \mathrm{~mm}$ and total length equal to $165 \mathrm{~mm}$ were used (4). In the case of shell-and-coil TES the coil has been also made of a copper tube but with an outer diameter $\mathrm{d}=6 \mathrm{~mm}$. The total length of the tube was $460 \mathrm{~mm}$. However, the length of the tube element that has been used in the process of bending the coil had a total length equal to $360 \mathrm{~mm}$. The rest of the tube was straight. The coil pitch was $15 \mathrm{~mm}$ and the outer coil diameter was $26 \mathrm{~mm}$. The experiments have been conducted for the coil position at the top and the bottom of the tank. The results showed the influence of heat transfer geometry for phase change efficiency. The article presents the thermal characteristic of melting and solidification phenomena as well as their visual analysis. A significant impact of heat transfer geometry at the shape of the melting and solidification profile. The optimal performance has been achieved for shell-and-coil TES with a coil arranged at the top of the tank.
\end{abstract}

Keywords: melting; solidification; phase change material (PCM); shell-coil; annular

\section{Introduction}

It is well known that increasing pollution influences global temperature growth and the deterioration of living conditions. One of the possible solutions to stop these adverse changes is the pursuit of energy-saving. The energy could be utilized better if the energy system cooperates with the energy magazine [1]. The TES system can shift the demand for cooling/heating in time and due to that fact enhance energy efficiency [2]. The latent heat thermal energy storage is very popular because of their high energy density and close to a constant temperature of charging/discharging. However, the PCM's conductivity is relatively low, which is deterioration the heat transfer efficiency. One of the possibilities to deal with that problem is to optimize the heat transfer area.

Recent studies have shown the possibility to significantly decrease charging/discharging processes by enhanced heat transfer rate by taking into account the influence of natural convection. Mao et al. numerically investigated a novel truncated cone thermal energy storage unit with phase change material. This study has shown a significant decrease in the charging/discharging time in the case of truncated cone TES geometry compare to cylindrical TES [3]. Pourakabar and Darzi [4] numerically studied the possibility of heat transfer enhancement during the melting and solidification process in a cylindrical thermal energy storage unit. The authors presented CFD calculation results for different 
shell shapes and different arrangements of the inner pipe. It has been observed that in the case of melting phenomena the conduction mechanism is dominated only in a short period at the beginning of the charging process, after that the natural convection mechanism is crucial for phase change time (heat transfer efficiency). The highest melting rate has been observed for a cylinder with two tubes in a vertical array. What is more, for the solidification process the best option was to use geometry with four tubes in a diamond array. It should be noted that the geometry of working elements has been set to obtain the same volume of PCM inside thermal energy storage units. The article also analyzed the possibility to use metal foam to enhance heat transfer. Results indicated that it is possible to decrease the melting or solidification time by up to $90 \%$. Unfortunately, it has been observed that metal foam decreases the influence of natural convection at the phase change processes. Mahdi et al. [5] experimentally studied the melting phenomena of paraffin wax in a conical coil thermal energy storage unit (TES). The obtained results indicated that TES with the conical coil, compared with the helical coil type, significantly enhances heat transfer. Depending on the inlet temperature of working fluid at the coil between $20.97 \%$ to $28.32 \%$. The authors noted that the increase of melting process efficiency was mainly an effect of an increase in the heat transfer area at the bottom region of the tank. In the author's opinion, the shape of the conical coil indicated strong convection currents in the bottom region. These currents increased the melting process also at the top region of the tank, where the heat transfer area was smaller. Al-Abidi et al. [6] numerically investigated the melting process of RT82 as PCM in the triplex tube heat exchanger. The article presented an analysis for different design and operation parameters such as fin length, kind of material, and thickness or Stefan number. The most significant influences at heat transfer during the melting process were fin length and number of fins. Sun et al. [7] experimentally worked at heat transfer enhancement caused by natural convection during the melting of different kinds of PCM. The study presented results for different scanning calorimetry (DSC) as well as results carried out on a macro scale. It was found that experimentally received temperature ranges needed for melting exceeded those obtained by the DSC tests. Furthermore, the melting time is a function of the thermal energy storage unit orientation. In the case of vertical orientation influence of natural convection can decrease melting time equal to $45 \%$. However, for horizontal TES orientation, that time was longer than the solidification process for the same geometry.

Zhao et al. [8] presented numerical results for shell tube latent thermal energy storage units. Results confirmed that using the optimized fin number can decrease the melting time by over $60 \%$. Furthermore, the additional reduction of time can be obtained by appropriately modifying bottom fins lengths and intervals. What is more, in the result as of CFD calculations for PCM storage with three kinds of metal foams (nickel, aluminum, and copper). Finally, it was confirmed that by using optimized fins geometry it is possible to obtain comparable efficiency of the melting process as in the case of metal foam using. Sciacovelli et al. [9] also worked at the possibility to use optimized geometry fins to maximize the performance of LHSS (latent heat storage system). The authors analyzed the Y-shaped fins geometry by CFD code. It has been shown that by the implementation of optimized heat surface geometry it is possible to obtain an increase of system performance above $20 \%$ compared to not optimized geometry. What is more, in the presented study it was indicated that preferred geometry should be different for different operating times. For a long-term operating time, it is better to use Y-shaped fins with wide angles between branches. However, for the short operating time, it is better to use smaller angles. Chen et al. [10] numerically investigated the performance of the PCM thermal energy storage unit with metal foam enhancement. The metal foam was used to enhance heat transfer inside the PCM substance as well as at the side of fluid flow. The article presented a calculation procedure that was used to model the solidification/melting process during the discharging/charging process of the storage tank. The use of foam significantly increased heat transfer on both sides. The time of phase change decreased more than $84 \%$ using metal foam on both sides (at PCM and working fluid sides), compared to $40 \%$ in the case of using the metal foam only on the phase change material side.

The increase of thermal efficiency of latent energy storage units can be achieved also by modification of PCM properties. Nitsas and Koronaki [11] modeled organic phase change material phase change 
by CFD and computational methods. The authors proposed to enhance material conductivity with nanoparticle additives. The results showed that copper nanoparticle additives can enhancement the melting process between $5.5 \%$ and $6.5 \%$ compare to pure PCM. Hajizadeh et al. [12] numerically studied water solidification phenomena. The conductivity of water was increased by nanomaterial additives. The study presented results for nanomaterials with different shapes and different dispersion levels. It was noted that charging time is related to the shape of nanoparticles. The additives of nanoparticles to PCM can decrease phase change time at about $2.35 \%$ for a nanoparticle with brick shape to $7.14 \%$ for nanoparticles with platelet shapes. Mohammed Reza Hajizadeh et al. in their next study [13] studied the solidification of RT35 within a tank with longitudinal-Y shape fins and nanoparticle additives. The three different geometries were exanimated: shell tube without fins, and shell tube with two different fins arrangement. What is more, the influence of $\mathrm{CuO}$ nanoparticles was analyzed. The significant influence of nanomaterials additives in the solidification process was confirmed.

In the literature, there are also many studies concerned with the optimization of coil tube geometry to diminish the limited performance of LHSS. Chen et al. [10] investigated an experimentally and numerically latent thermal storage system with a spiral coil tube. As a phase change material was used a commercial paraffin wax with graphite composite to enhance thermal conductivity. The numerical simulations for heat transfer at phase change of PCM, presented in the study, had good agreement with experimental results. Authors claimed that the mass flow of working fluid had a small influence on LHSS performance especially if the Reynolds number was high $(\operatorname{Re}>8700)$. However, the temperature difference had a big influence. It was highlighted also that the significant influences at heat transfer during melting/solidification of PCM had a ratio of the spiral coil helix radius of the tube radius of the PCM tank. It was noted that the preferred values of that parameter should be between 0.53 and 0.63 . Mahdi et al. [14] experimentally and numerically studied the possibility to increase heat transfer during the melting of PCM by using a double-pipe helical-coiled tube. The performance of the proposed geometry of the thermal energy storage unit was investigated for different operation conditions and orientations of the unit (vertical and horizontal). The results revealed that the melting time is approximately $25.7 \%$ to $60 \%$ lower respectively for horizontal and vertical orientation, compared to a straight double-tube latent thermal storage unit in the same orientations. It was noted also that significant influences at melting performance have coil pitch as well as Reynolds number and initial temperature of working fluid. Anish et al. [15] experimentally investigated the performance of energy storage with erythritol/xylitol as PCM in a vertical double spiral coil unit. The authors presented an analysis of experimental data for the charging/discharging process at different operating conditions (flow rate of working fluid and different inlet temperature of it). The study concluded that a double coil storage unit provided good performance. Better heat transfer efficiency was obtained for the melting process. It was highlighted that this is the effect of bigger natural convention influence compare to solidification. In the same operation condition, the higher energy was stored in PCM container filled with erythritol. However, the discharging process is diminished in the case of erythritol due to the appearance of subcooling phenomena. Castell et al. [16] experimentally and theoretically analyzed a coil tank geometry as a potential for a PCM storage tank for cooling applications. The theoretical analysis was performed for the storage unit assumed as a heat exchanger working with one fluid and constant temperature heat sink (energy source-PCM). The two different designs of geometry were tested. It was noted that the coil-tank thermal storage unit can deliver a constant outlet temperature during the phase change process. It was indicated that the coil in the tank storage unit had high performance and provided effective heat transfer. The authors presented their own experimentally function for the effectiveness of the thermal energy storage unit. This equation was only a function mass flow rate of working fluid and heat transfer area. The authors concluded that such a simple approach can be used to design PCM storage units. Ajarostaghi et al. [17] numerically analyzed the melting process of ice in shell and coil latent thermal energy storage unit. The article presented CFD calculations results prepared in commercial ANSYS Fluent 18.2.0 code. The influences of the inlet water parameter, as well as the flow rate of the working fluid, were investigated. What is more, the coil 
geometrical parameters such as coil diameter, pitch, and height were analyzed. The authors confirmed the results of earlier experimental and numerical studies that either inlet temperature or flow rate increases the efficiency of the melting process. In that study, it was highlighted also that the coil diameter, compared to other geometrical parameters, was the biggest influence in heat transfer during the melting of ice.

Undoubtedly, due to the low thermal conductivity of phase change material and the complex physics of heat transfer during the melting/solidification, it is very important to optimize the geometrical configuration of TES. However, due to high costs and technical limitations, rectangular and cylindrical geometries of storage tanks are still popular [18]. The main aim is to find low-cost, simple to manufacture geometry with high heat transfer characteristics. The authors of the present study proposed a new geometry of the shell-and-coil storage unit. The study aims to optimize the rate of melting/solidification process by changing the coil tube position in the TES tank. The experimental investigation has been carried out for the melting/solidification of coconut oil in the case of annular PCM storage (reference geometry) and shell-and-coil TES with two different coil positions. Coconut oil seems to be a perspective for use in thermal energy storage systems. Most of the experimental/theoretical studies in the open literature have been concerned with eutectic mixtures or single compound substances. It has been highlighted that the melting/solidification process is much more complex for non-eutectic mixtures and some limited analytical models could be used to design TES working with such substances.

The primary objective of the present study is to provide a comprehensive experimental database including multiple temperature profiles in the transition and melting and solidification process. The authors have chosen natural substances like coconut oil because of fact that it is easily commercially available and cheap. What is more relevant, this oil is non-toxic can and abundant in nature. Because the coconut palm plant can absorb and use saltwater during growth, it has a big advantage due to the limited resources of sweet water in the world. Most of the artificially generated PCMs are substances difficult to utilize. What is more, this substance has relatively good thermophysical parameters (e.g., conductivity larger than $0.3 \mathrm{~W} / \mathrm{mK}$ ).

The article is divided into four sections namely; this introduction, Section 2 which presents the test section and describes the used research methodology, Section 3 with the results of the research are finally Section 4 which summarizes the most important conclusions from this study.

\section{Experimental Test Section}

The experimental test rig scheme has been shown in Figure 1. The test section consists of a circuit with an ultra-thermostatic bath. The distilled water serves as the heat transfer media, its temperature is measured by Pt100 resistance sensors. While the melting case is studied, the working fluid is heated by the thermostat at a precisely controlled temperature. In the case of solidification, the thermostat is cooled with externally chilled water. The temperature profile inside of the PCM is measured with 20 sensors. All temperature sensors are connected to the NI cDAQ-9189 data acquisition system, shown in Figure 2.

Collected data are sent to the PC with NI CDAQ acquisition system. The special software to collect data was made in Lab View software. The block diagram made in Lab View software as well as the working window has been shown in the figure below.

The phase change melting/solidification process is observed also by the high speed camera. The amount of water flow through the experimental module working element has been set to obtain the constant wall conditions for all experiments. Additionally, the shell temperature field was observed by an infrared camera to estimate heat losses. It should be stress that to minimalized heat losses experimental only $25 \%$ of the shell surface has been observed, the rest was covered by polyurethane insulations (see Figure 3) To obtain a better quality of melting/solidification phase change front also the special photographic lamps have been installed. 


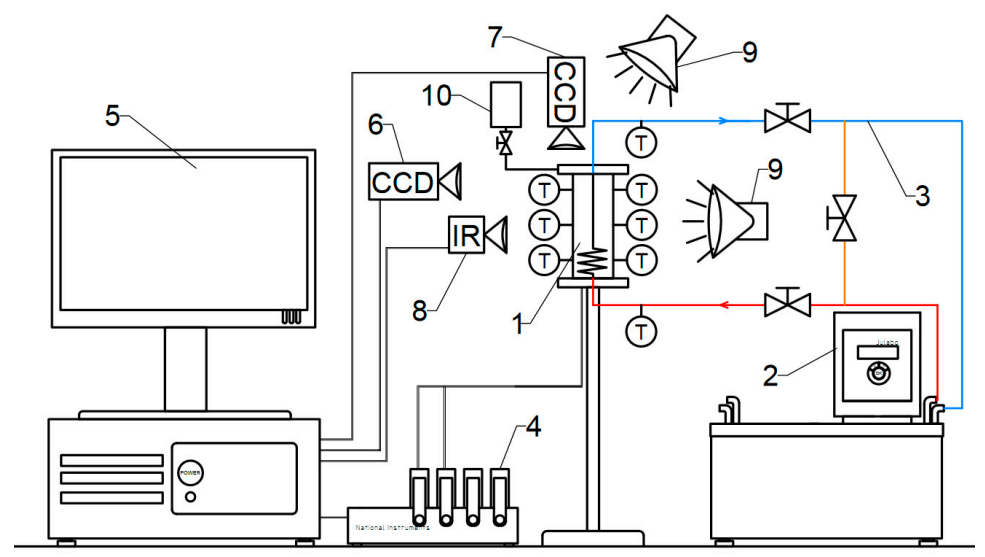

Figure 1. Scheme of experimental test section: 1 -experimental module; 2 -thermostat with bath; 3-thermostatic loop; 4-data acquisition system; 5-PC; 6-front camera; 7-top camera; 8-thermal imaging camera; 9-photographic lamps; 10—filling vessel.

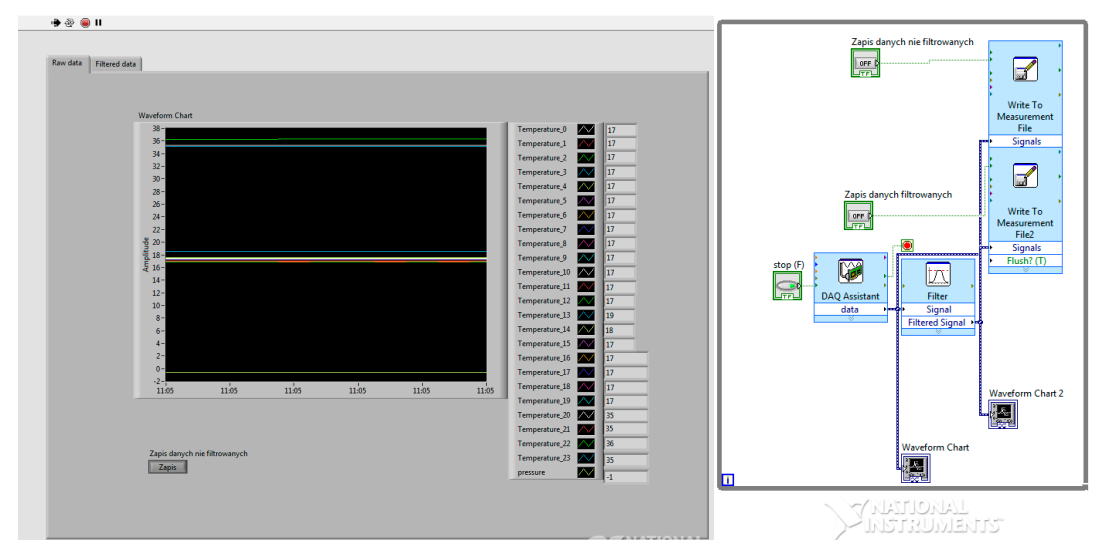

Figure 2. Data acquisition system software: at the left working window, at right block diagram.

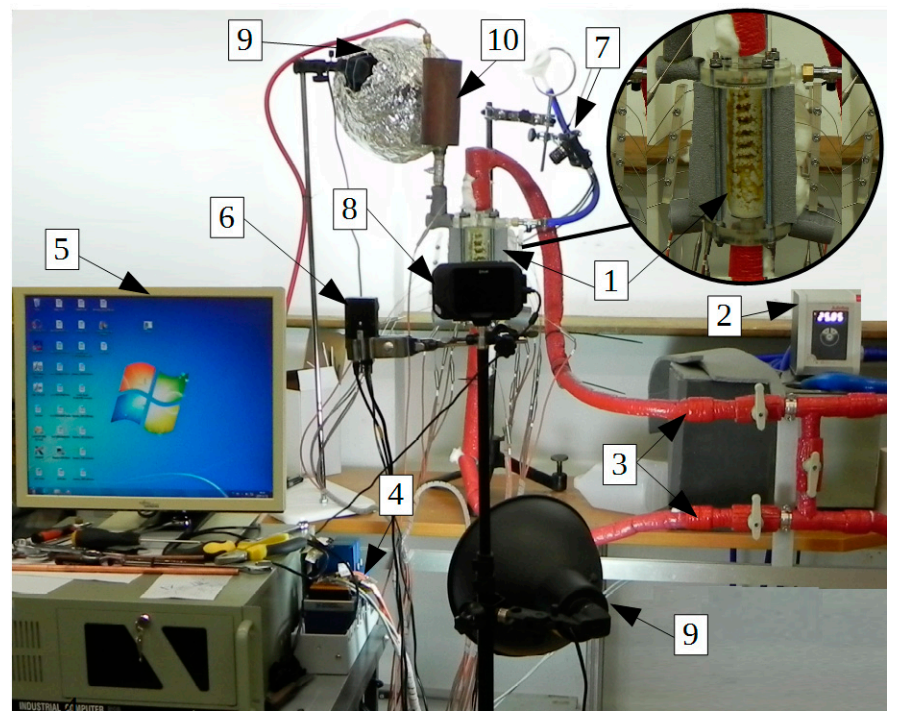

Figure 3. View of experimental test section: 1-experimental module; 2-thermostat with bath; 3-thermostatic loop; 4-data acquisition system; 5-PC; 6-front camera; 7-top camera; 8-thermal imaging camera; 9-photographic lamps; 10—filling vessel. 
The experimental module configurations and the arrangement of temperature sensors inside the module have been presented in Figure 3.

Figures 4 and 5 present the project of the demountable thermal module. Due to the demountable construction, it is possible to easily replace the working element in the experimental test section. What is more the special mounting system for thermocouples enables us to change the sensors' radial position. The experimental tank was made from PMMA to allow observation of the shape of phase change front during melting/solidification processes. It should be also noted that this material is easily workable and has low conductivity which is important to minimalize heat losses to the environment. The external diameter of the vessel is equal to $50 \mathrm{~mm}$ and the material wall thickness is equal to $5 \mathrm{~mm}$. It should be added that also the flanges were made from PMMA with $110 \mathrm{~mm}$ diameter and $20 \mathrm{~mm}$ thickness. As can be seen in Figure 6 the flanges and the jacket were mounted together by using four M8 threaded steel rods (7) and appropriate nuts and washers. To seal the jacket and the flanges the rubber gaskets were used. The additional rubber elements (rubber pads) were also used to compensate for the thermal expansion of the module during the phase change process. In the case of annular TES, the copper tube with outer diameter $d=10 \mathrm{~mm}$ and total length equal to $165 \mathrm{~mm}$ were used (4). In the case of shell-and-coil TES the coil has been also made of a copper tube but with an outer diameter $\mathrm{d}=6 \mathrm{~mm}$. The total length of the tube was $460 \mathrm{~mm}$. However, the length of the tube element that has been used in the process of bending the coil had a total length equal to $360 \mathrm{~mm}$. The rest of the tube was straight. The coil pitch was $15 \mathrm{~mm}$ and the outer coil diameter was $26 \mathrm{~mm}$. The main assumption was to keep the same volume occupied by the heat transfer element in the case of annular TES and shell-and-coil TES.

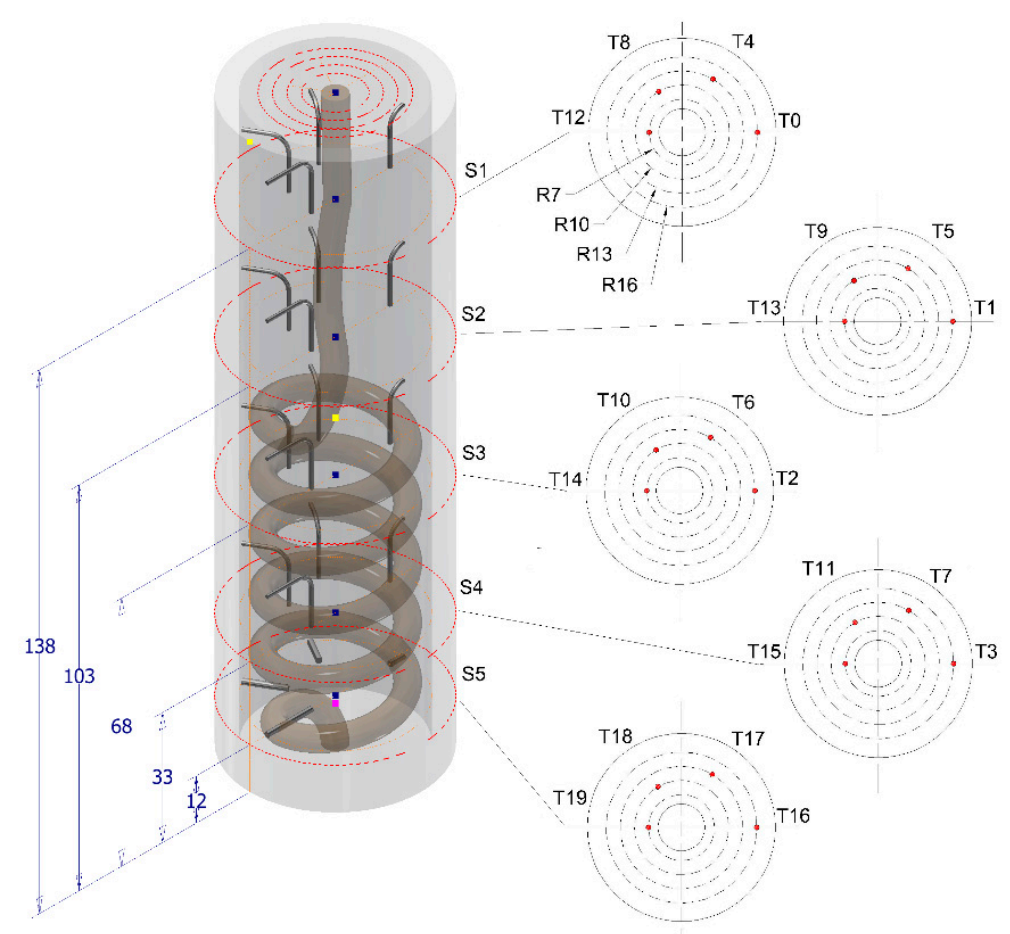

Figure 4. Arrangement of temperature sensors inside the experimental module with coil working element: S1 to S5 surfaces in subsequent cross-sections. 


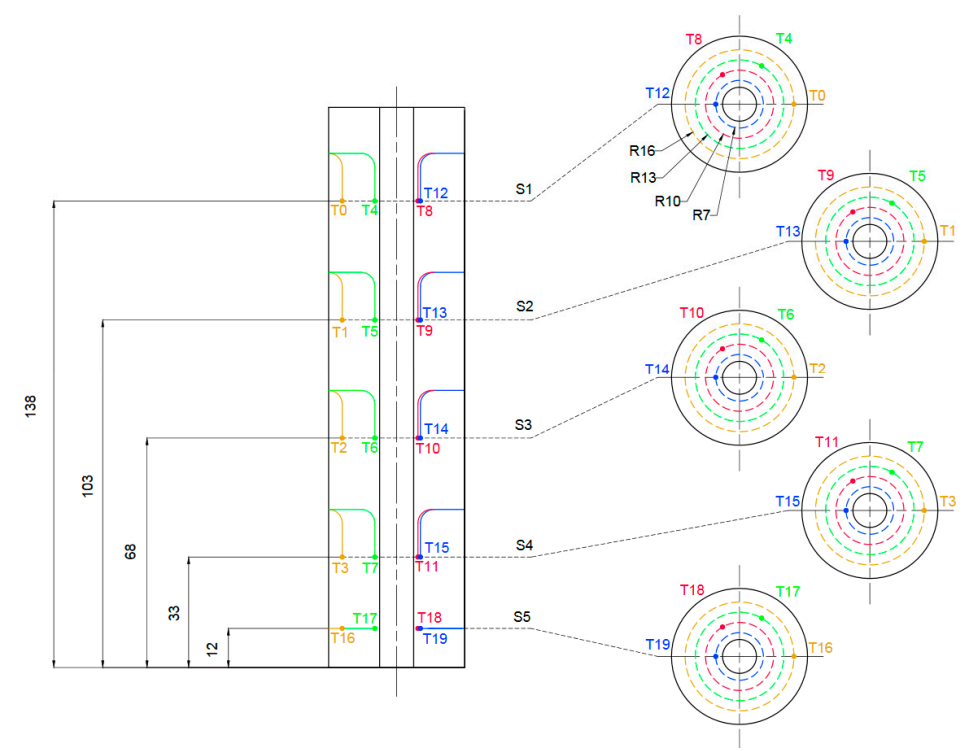

Figure 5. Arrangement of temperature sensors inside the experimental module with a straight working element: S1 to S5 surfaces in subsequent cross-sections.
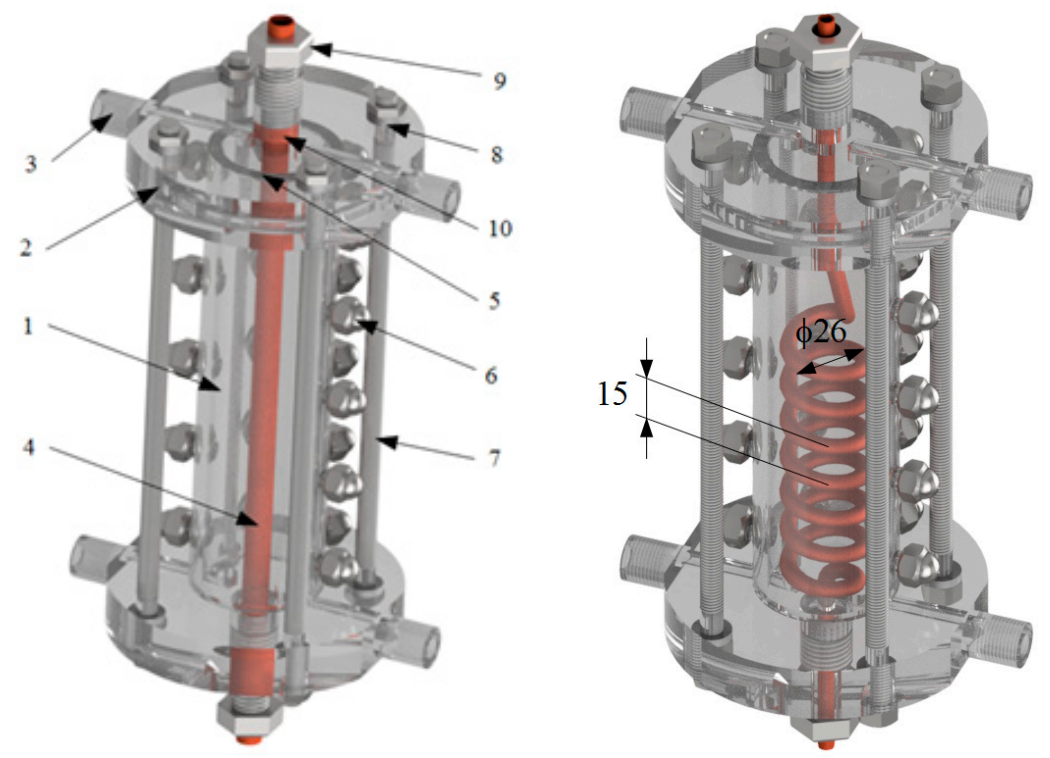

Figure 6. View of the experimental module, at left-with straight working element, at right with coil working element: 1-jacket; 2-flanges; 3-stubs; 4-replaceable working element; 5-rubber gasket; 6-temperature sensors glands; 7 -threaded steel rods; 8-rubber pads; 9 -working element glands; 10 -gasket.

\section{Experimental Investigation Results Analysis for the Melting/Solidification Process in Reference TES and Novel Shell-and-Coil TES Tank}

\subsection{Heat Transfer Characteristic during Solidification Processes}

From Figures 7-9 it can be seen that the performance of solidification is better in the case of shell-and-coil TES with coil position at the upper of the tank. The intensification is gathered at the bottom part of the tank. It could be explained by the buoyancy force influence. The coil is arranged at the top of the tank enhanced heat transfer. The convection currents push the cold fluid and the solid particles at the bottom of the tank. In the case of a coil arranged at the bottom of the tank, the fluid is stratified. The hot fluid gathered at the top and cold at the bottom of the tank. The solidification is very fast in the bottom region, however, in the upper region, the heat transfer geometry is significantly 
lower. There is heat transfer domination by conduction between the upper region and the rest of the tank volume. In all experimentally studied geometries, it is a visible appearance of the subcooling phenomenon (see Figure 9). The values of subcooling temperature were different for different analyzed surfaces (S1 to S5). However, for annular TES geometry, this parameter was not changed significantly depending on the location in the tank volume. However, in the case of TES with coil position at the upper of the tank the lowest values of subcooling temperature were observed for S2 and S3 (see Figures 7 and 8). What is more in the case of TES with coil position at bottom of the tank the lowest values of subcooling temperature were observed for S3 and S4. In the case of the surface located at the lowest position inside the tank, there was no significant difference. This could be explained by the fact that the heat transfer intensity was different in different tank zones for geometries with shell and coil TES. Generally, the subcooling temperature is a function of radial position. It has been confirmed that this parameter is the lowest close to the heat transfer surface. It is confirmed the crucial influence of natural convection influence on solidification phenomena in the case of the use of asymmetric geometries. In the case of annular TES geometry the natural convection effect is dominated at the beginning of the phase change process, then it is diminished.

The temperature profiles recorded versus time clearly shown the period of the plateau during the phase change increased with the growing radial distance from the heat transfer surface. Generally, all of the temperature profiles drop until they reach a subcooling point then rise until phase change temperature is reached. After that temperature stabilizes during the phase change process and again drops to until it will reach the temperature of the heat transfer surface. The drop in temperature after the plateau is signalized the end of the solidification process. Due to that fact, there is a visible difference between temperature profiles. What can be influenced by different heat transfer surface area in different tank zones. What is more the radial distance between temperature sensors in the case of the cylindrical tank and TES with coil geometries are different. For example, the temperature profiles on surface S1 indicate that for all experimental time there is no end of phase change in the case of coil arranged at the bottom (see Figure 7).

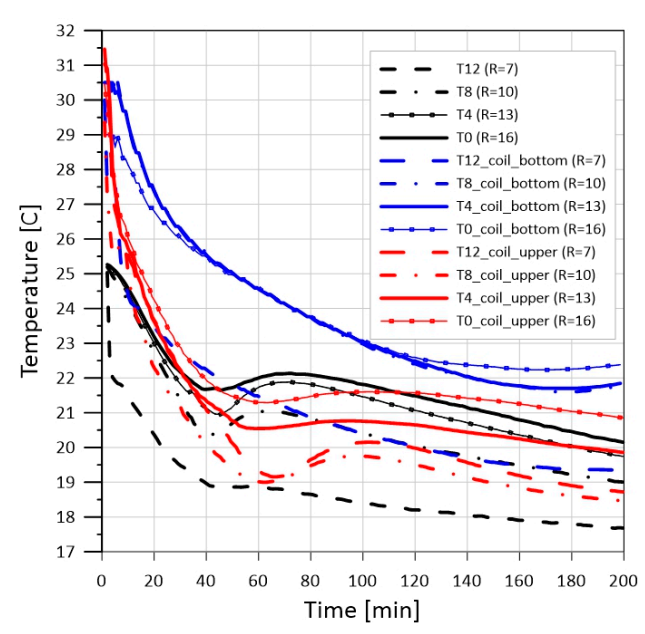

(a)

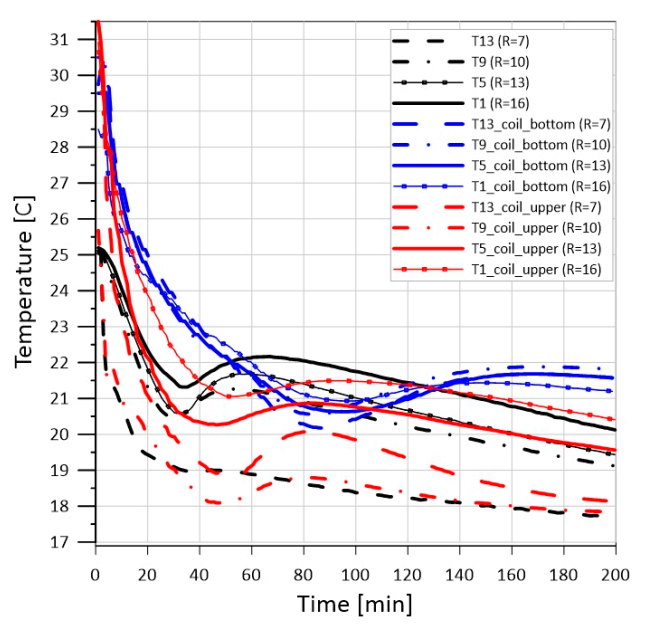

(b)

Figure 7. Temperature profile evolution as a function of the radial position during the solidification process with constant wall temperature condition $\left(T_{s}=17^{\circ} \mathrm{C}\right)$ on surface $\mathrm{S} 1(\mathbf{a})$ and $\mathrm{S} 2(\mathbf{b})$. 


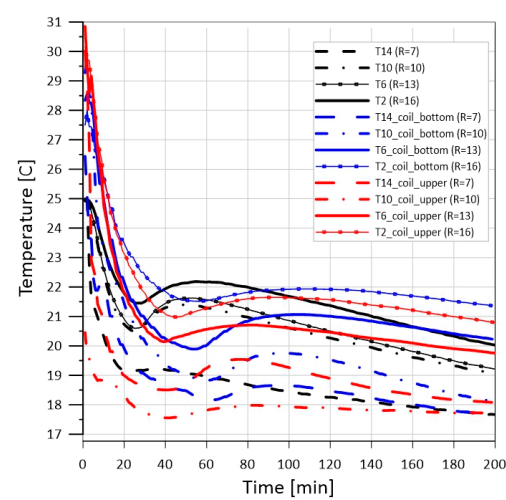

(a)

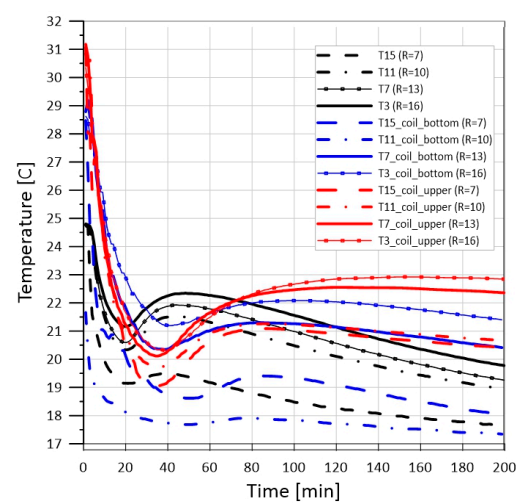

$(\mathbf{b})$

Figure 8. Temperature profile evolution as a function of the radial position during the solidification process with constant wall temperature condition $\left(T s=17^{\circ} \mathrm{C}\right)$ on surface S3 (a) and S4 (b).

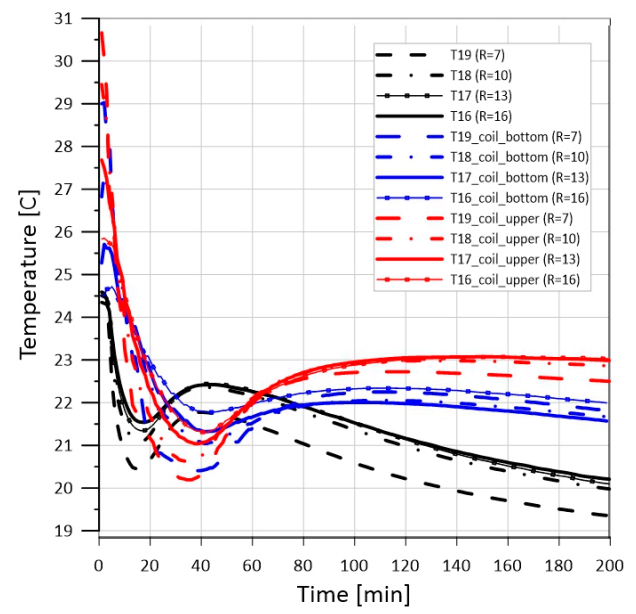

Figure 9. Temperature profile evolution as a function of the radial position during the solidification process with constant wall temperature condition $\left(T s=17^{\circ} \mathrm{C}\right)$ on surface S5.

\subsection{Visual Analysis of Solidification Processes}

The process was simultaneously visually observed, Figures 10-13 present the melting process in three geometries for a specified time.

At the beginning of solidification in all cases, a thin layer is formed at the heat transfer surface. However, the solid phase is created also at the whole volume of the PCM. In the case of shell-and-coil TES with coil position at the bottom of the tank, this phenomenon is strongest initiated. Inside the annular TES geometry, it is confirmed to appearance truncated cone shape of the solidification front (see Figure 11). Similar results have been numerically received by Mao et al. [3]. The solidification of coconut oil is very fast close to the coil geometry in both geometrical positions. Nonetheless, it should be noted that phase change is faster for shell-and-coil TES with coil position at the top of the tank (see Figure 10). This could be explained by the influence of the natural convection effect. When the heat transfer surface is larger at the bottom of the tank, the solidification is very fast at the beginning of the process. After all, the natural convection influence is diminished when the whole volume of PCM close to the coil becomes solid. The small heat transfer area at the top of the tank is not sufficient to sustain the intensity of the process. The situation is opposite in the case of shell-and-coil TES with coil position at the top of the tank, the solid phase is created very fast in the whole volume of the tank. By the buoyancy force, heavy pieces of the solid body fall at the bottom of the tank and the hot fluid is pushed to the top of the tank where it is cool by the large heat transfer surface of the coil. The shell-and-coil unit with a coil arranged at the top of the tank has the best performance (see Figure 13). The shell-and-coil 
TES with coil arranged at the bottom region of the tank has comparable performance to the simple annular TES geometry. A similar result has been received by Seddegh et al. [19]. They have been experimentally studied cylindrical and conical-coil TES units during the melting and solidification process. The conical coil was characterized by a decreased heat transfer area from the bottom to the top of the tank. In the presented study a similar situation was for shell-and-coil TES with coil position at the bottom of the tank. It has been confirmed that conical geometry a significant decrease in melting time. However, it has comparable thermal performance during the solidification process.

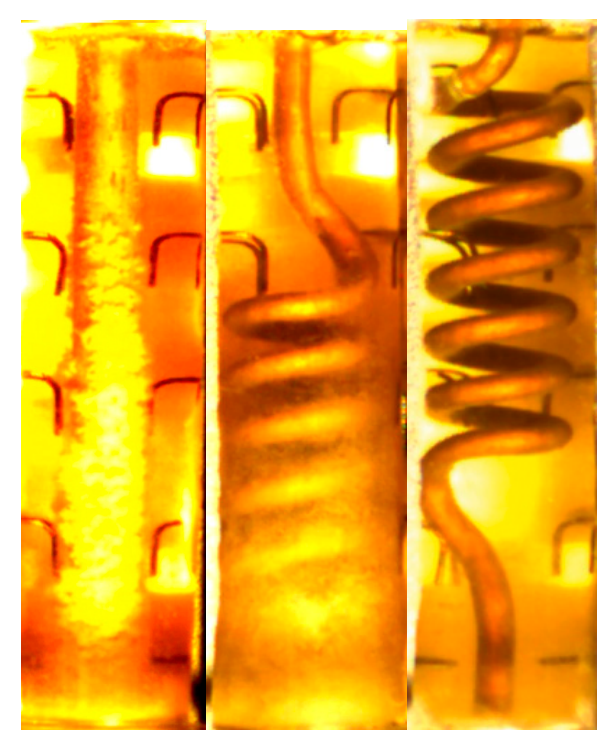

Figure 10. Solidification front images for different geometry of storage units but for the same process time equal to $10 \mathrm{~min}$ and the same constant wall temperature condition $\left(\mathrm{Ts}=17^{\circ} \mathrm{C}\right)$ : at left for annular TES, at the middle for shell-and-coil TES with coil position at the bottom of the tank, at the right for shell-and-coil TES with coil position at upper of the tank.

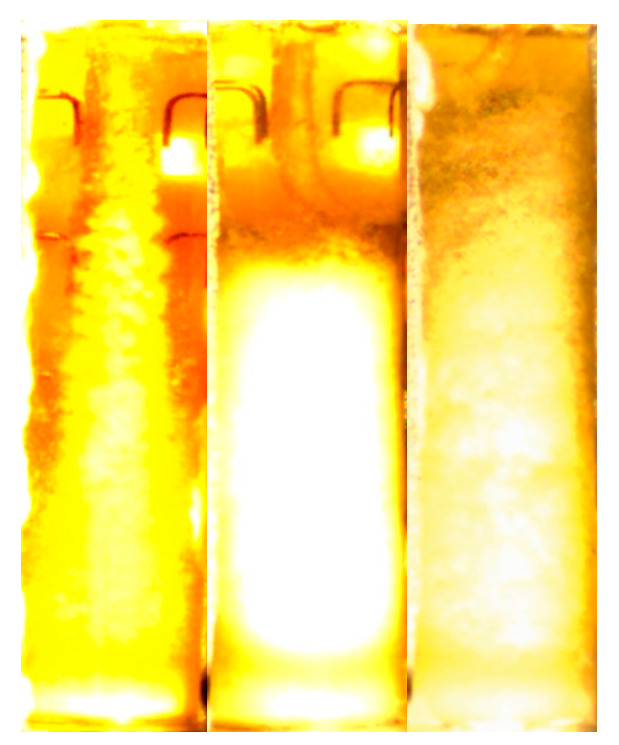

Figure 11. Solidification front images for different geometry of storage units but for the same process time equal to $20 \mathrm{~min}$ and the same constant wall temperature condition $\left(\mathrm{Ts}=17^{\circ} \mathrm{C}\right)$ : at left for annular TES, at the middle for shell-and-coil TES with coil position at the bottom of the tank, at the right for shell-and-coil TES with coil position at upper of the tank. 


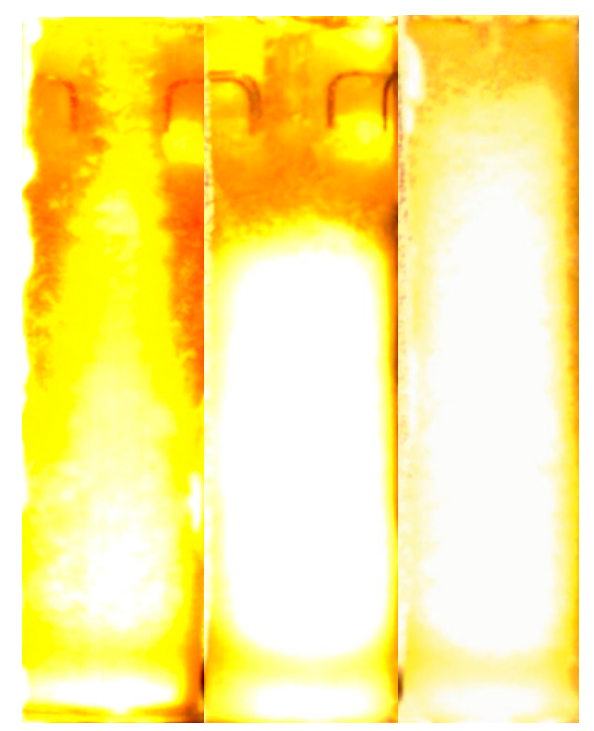

Figure 12. Solidification front images for different geometry of storage units but for the same process time equal to $25 \mathrm{~min}$ and the same constant wall temperature condition $\left(T s=17^{\circ} \mathrm{C}\right)$ : at left for annular TES, at the middle for shell-and-coil TES with coil position at the bottom of the tank, at the right for shell-and-coil TES with coil position at upper of the tank.

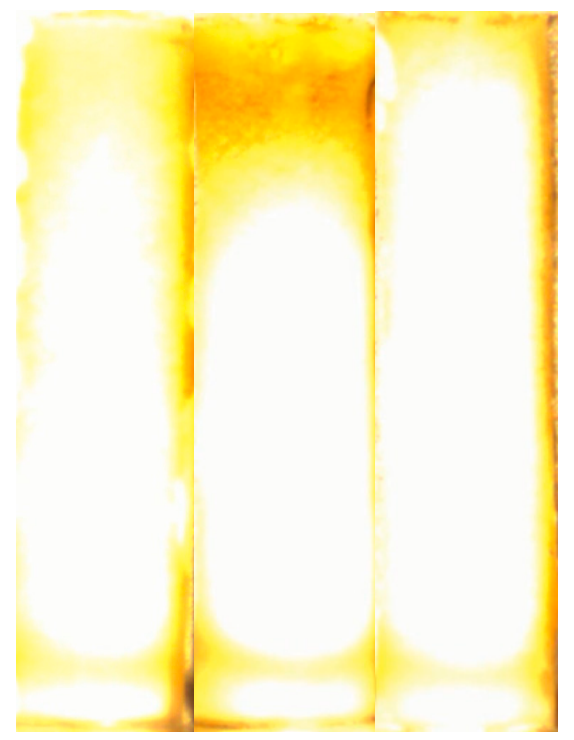

Figure 13. Solidification front images for different geometry of storage units but for the same process time equal to $35 \mathrm{~min}$ and the same constant wall temperature condition $\left(\mathrm{Ts}=17^{\circ} \mathrm{C}\right)$ : at left for annular TES, at the middle for shell-and-coil TES with coil position at the bottom of the tank, at the right for shell-and-coil TES with coil position at upper of the tank.

\subsection{Heat Transfer Characteristic during Melting Processes}

From Figures 14-16, it should be noted that both coil configurations enhanced the melting process compare to the simple annular geometry of TES. However, the shell-and-coil TES with coil arranged at the bottom region of the tank indicated the highest performance. In the shell-and-coil, TES with coil arranged at the top of the tank melting is very fast close to the coil surface. The temperature profiles rise significantly faster in the upper region than the bottom region of the tank (compare Figures 14 and 16). There is a disproportion between the rate of temperature growth with the upper region and bottom region of the tank. At the first stage, the conduction is dominated in the whole volume. However, after starting the melting process the most of the fluid is pushed up 
and gathered in the upper region where the convection mechanism dominated. At the bottom region, neither convection nor conduction mechanism has a domination role.

The highest temperature levels are reached closest to the heat transfer area. In this region, a sharp temperature rise can be observed. With the growing radial distance from the heat transfer surface, the temperature trends aren't as sharp. Nevertheless, all of the temperature profiles show the same stages. At the first stage, temperature undergoes a stable increase, with a domination of the heat conduction mechanisms. The next stage is characterized by smooth temperature growth. During this time the material is melting and absorbing latent heat. It ends with a sudden temperature rise, which could be explained by the convective flow in the liquid phase of the working fluid. Finally, a slow temperature rise until the heat source temperature is reached.

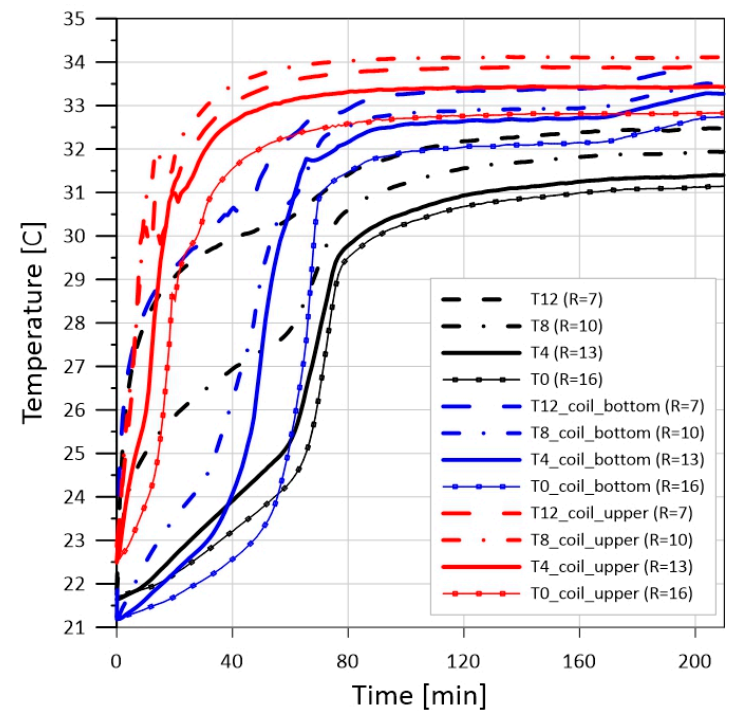

(a)

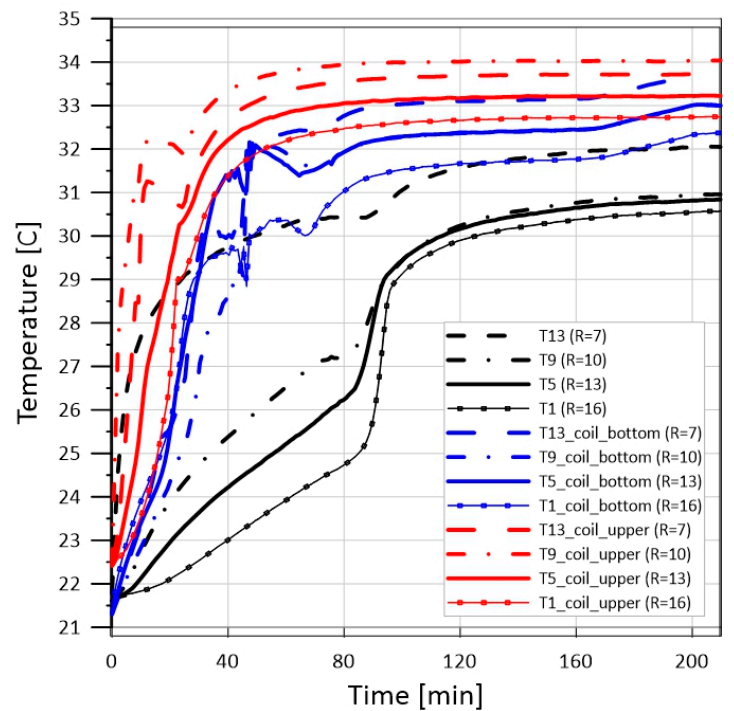

(b)

Figure 14. Temperature vs. time for increasing the radial position during the melting process with constant wall temperature condition $\left(T s=34^{\circ} \mathrm{C}\right)$ on surfaces: S1 (a) and S2 (b).

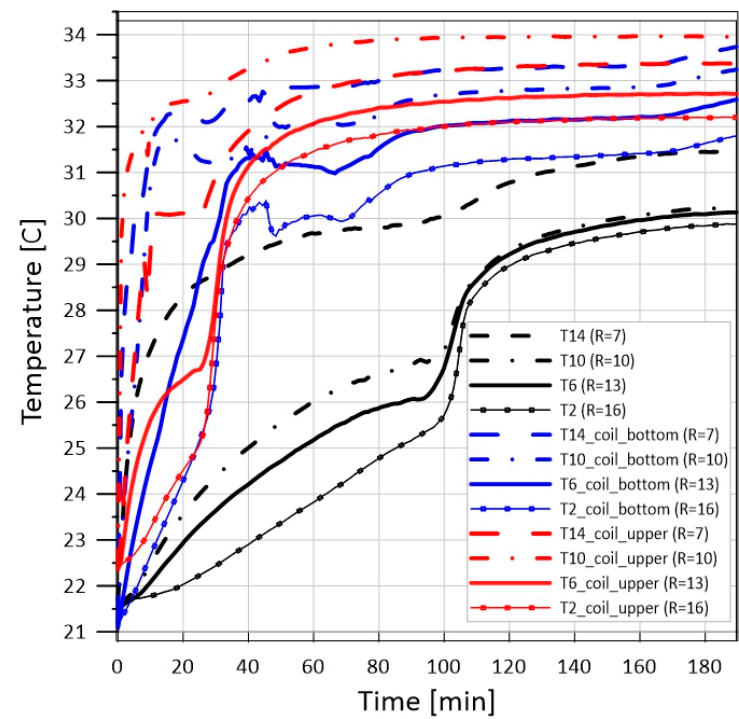

(a)

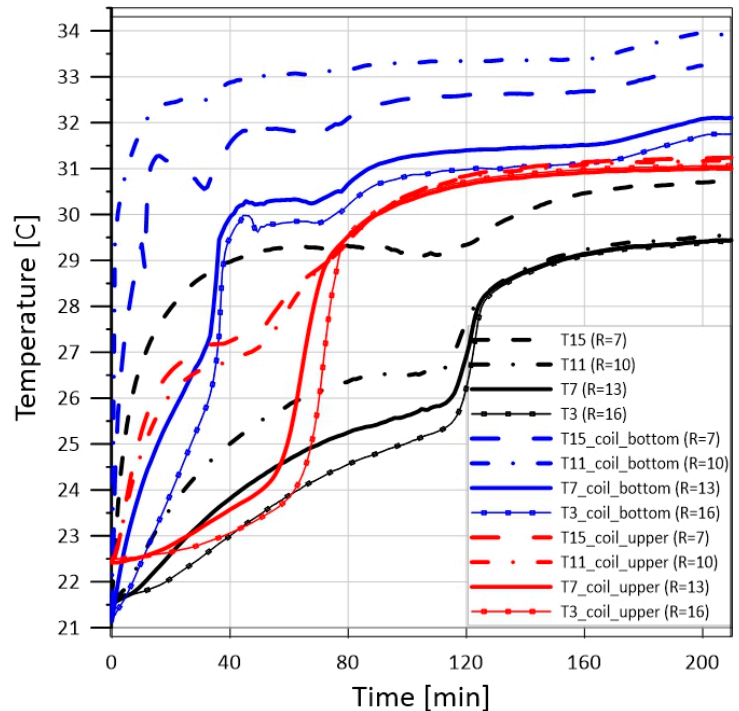

(b)

Figure 15. Temperature vs. time for increasing the radial position during the melting process with constant wall temperature condition $\left(\mathrm{Ts}_{\mathrm{s}}=34^{\circ} \mathrm{C}\right)$ on surfaces: S3 (a) and S4 (b). 


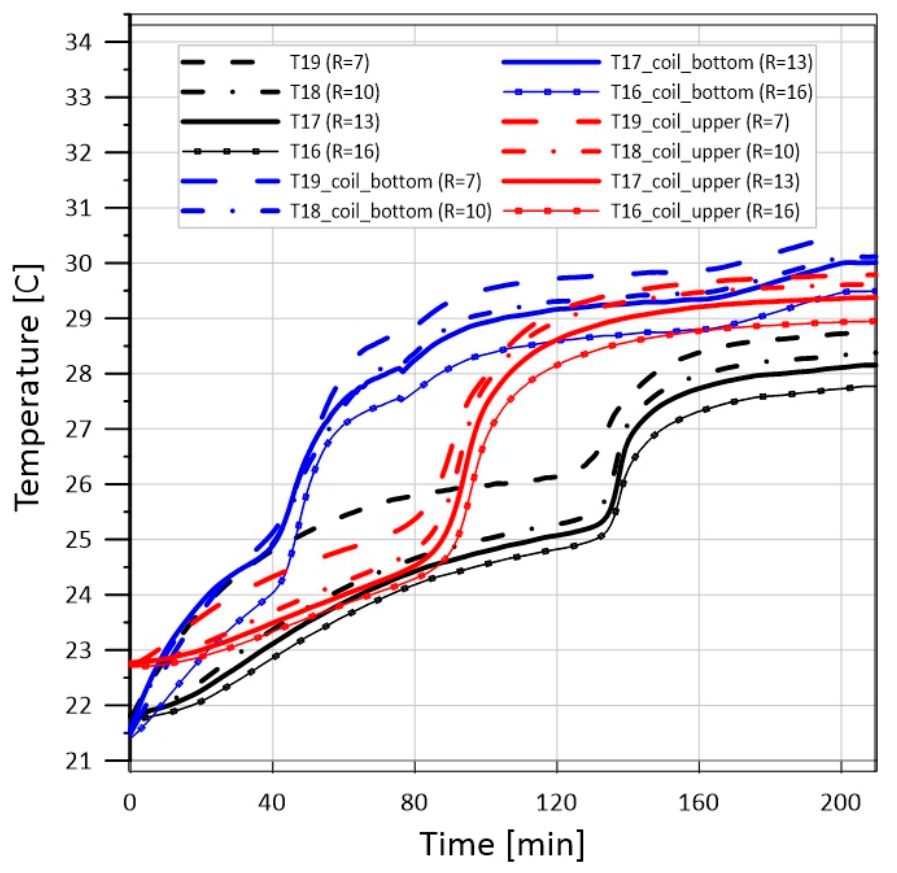

Figure 16. Temperature vs. time for increasing the radial position during the melting process with constant wall temperature condition $\left(T s=34^{\circ} \mathrm{C}\right)$ on surface S5.

\subsection{Visual Analysis of Melting Processes}

The process was simultaneously visually observed, Figures 17-20 present the melting process in three geometries for a specified time.

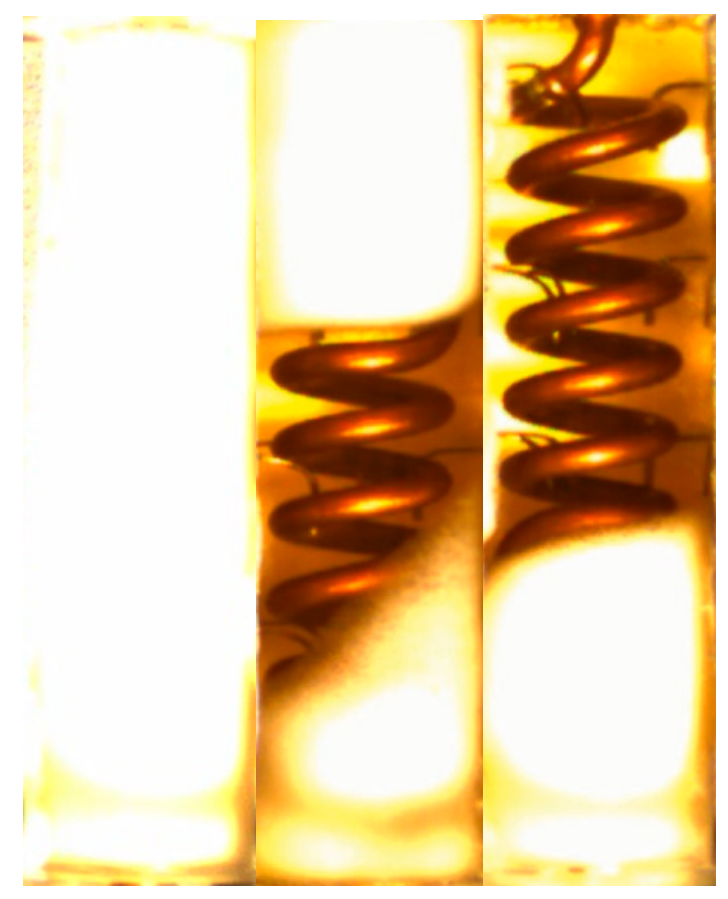

Figure 17. Melting front images for different geometry of storage units but for the same process time equal to $30 \mathrm{~min}$ and the same constant wall temperature condition $\left(\mathrm{Ts}_{\mathrm{s}}=34^{\circ} \mathrm{C}\right)$ : at left for annular TES, at the middle for shell-and-coil TES with coil position at the bottom of the tank, at the right for shell-and-coil TES with coil position at upper of the tank. 


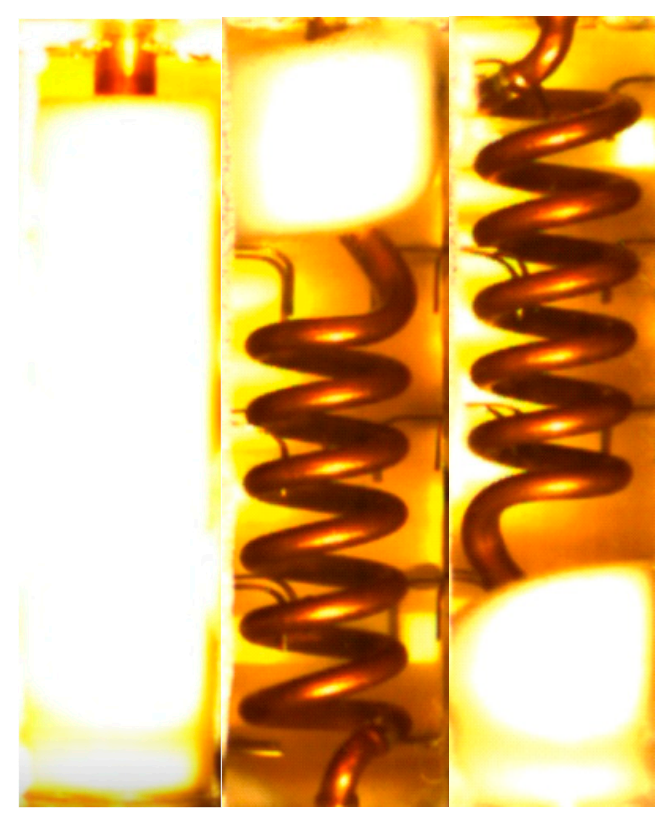

Figure 18. Melting front images for different geometry of storage units but for the same process time equal to $60 \mathrm{~min}$ and the same constant wall temperature condition $\left(\mathrm{Ts}=34^{\circ} \mathrm{C}\right)$ : at left for annular TES, at the middle for shell-and-coil TES with coil position at the bottom of the tank, at the right for shell-and-coil TES with coil position at upper of the tank.

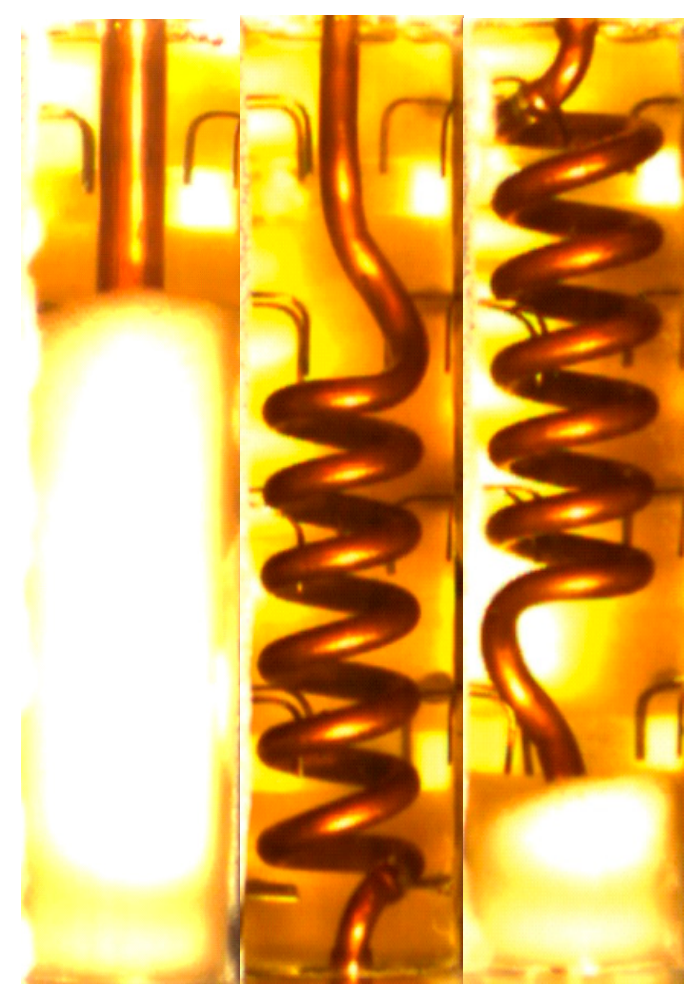

Figure 19. Melting front images for different geometry of storage units but for the same process time equal to $90 \mathrm{~min}$ and the same constant wall temperature condition $\left(\mathrm{Ts}_{\mathrm{s}}=34^{\circ} \mathrm{C}\right)$ : at left for annular TES, at the middle for shell-and-coil TES with coil position at the bottom of the tank, at the right for shell-and-coil TES with coil position at upper of the tank. 


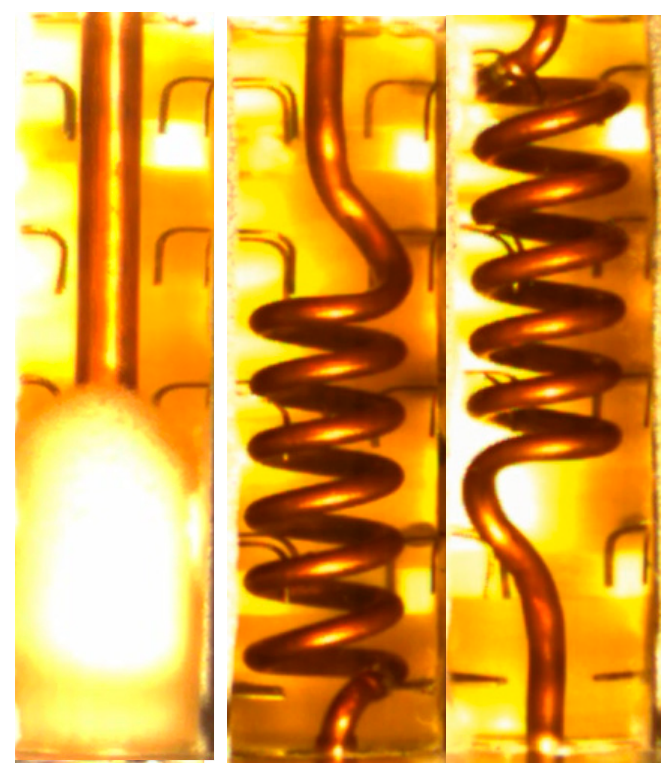

Figure 20. Melting front images for different geometry of storage units but for the same process time equal to $110 \mathrm{~min}$ and the same constant wall temperature condition $\left(\mathrm{Ts}=34^{\circ} \mathrm{C}\right)$ : at left for annular TES, at the middle for shell-and-coil TES with coil position at the bottom of the tank, at the right for shell-and-coil TES with coil position at upper of the tank.

At first, the melting process occurs close to the heat transfer surface. The circulation of the liquid phase more accelerated the melting process at the top of the tank in the case of annular TES and the TES with coil position at the top of the tank (see Figure 17). However, for the coil position at the bottom of the tank, the situation is the opposite. This is the effect of the largest heat transfer area located at the bottom of the tank. Finally, when the whole volume of PCM close to the coil becomes liquid, the melting process slows down (see Figure 19). Nevertheless, in the case of TES with a coil position at the bottom of the tank, natural influence is still significant. The solid body is located at the top of the tank. What is more, the solid fraction is too big to fall, so it is melted by hot fluid pushed by buoyancy force in the top zones of the tank. On the other hand, for TES with coil position at the top of the tank, the influences of convection currents are weaker. Furthermore, the heat transfer area is too small to sustain the intensity of the process. Despite the melting process is faster even in the case of TES with coil position at the top of the tank, compared to reference annular geometry. Similar observations for paraffin have been obtained by Zhang et al. [20]. The authors experimentally and numerically confirmed that, in the case of melting processes, the novel non-equidistant helical-coil structure is more effective than the equidistant helical-coil structure. It should be noted that the coil pitch of the non-equidistant helical-coil was smaller at the bottom of the accumulator. It is a similar situation to the shell-and-coil TES with coil position at the bottom which has been studied in the present article. Mahdi et.al. [14] proposed a conical shape of the coil with a larger diameter at the bottom and smaller at the top of the tank. They also used a similar approach as in the presented study. Namely, a geometry with a larger heat exchange surface on the bottom side of the TES has been proposed. The significant influence of natural convection on the melting process has been confirmed. The authors indicated that the conical coil geometry can significantly decrease melting time and increase the thermal performance of the process.

\subsection{Collective Analysis}

The schematic view of the heat accumulator is shown in Figure 6. The convective and conductive mechanisms in the PCM are complex and affected by the container and heat transfer geometry. To directly compare three of the tested geometries averaged values of temperature were used. The volume of the PCM was subdivided into the cylindrical sections with measured temperature 
(thermocouples $T_{0}$ to $T_{19}$ ). Volume averaged temperature of PCM at a given time is the sum of the measurements scaled by their influence volume:

$$
\bar{T}=\frac{\sum\left(T_{i} \cdot v_{i}\right)}{V}
$$

where $V$ is the total volume of the PCM and $v_{i}$ is the volume with corresponding measured temperature $T_{i}$.

All the test case results were transformed into the dimensionless temperature:

$$
\theta=\frac{\bar{T}-T_{S}}{\overline{T_{i}}-T_{S}}
$$

where $\bar{T}, \overline{T_{i}}$, and $T_{s}$ are the volume-averaged temperature of PCM at a given time, the volume-averaged temperature of PCM at the initial moment, and the heat transfer surface temperature.

Figure 21 presents a comparison of the melting experiments. As in all of the cases, the thermal capacitance is identical due to the same volume of the PCM, the heat transfer resistance will affect the differences in the process [21]. As can be seen coiled surface decreases the thermal resistance of the accumulator in both configurations.

During the solidification process presented in Figure 22, the difference between the test cases is less pronounced but still, the configuration with a coiled surface on the top of the PCM accumulator has a slightly lower thermal time constant, which is consistent with the results of the visual observations.

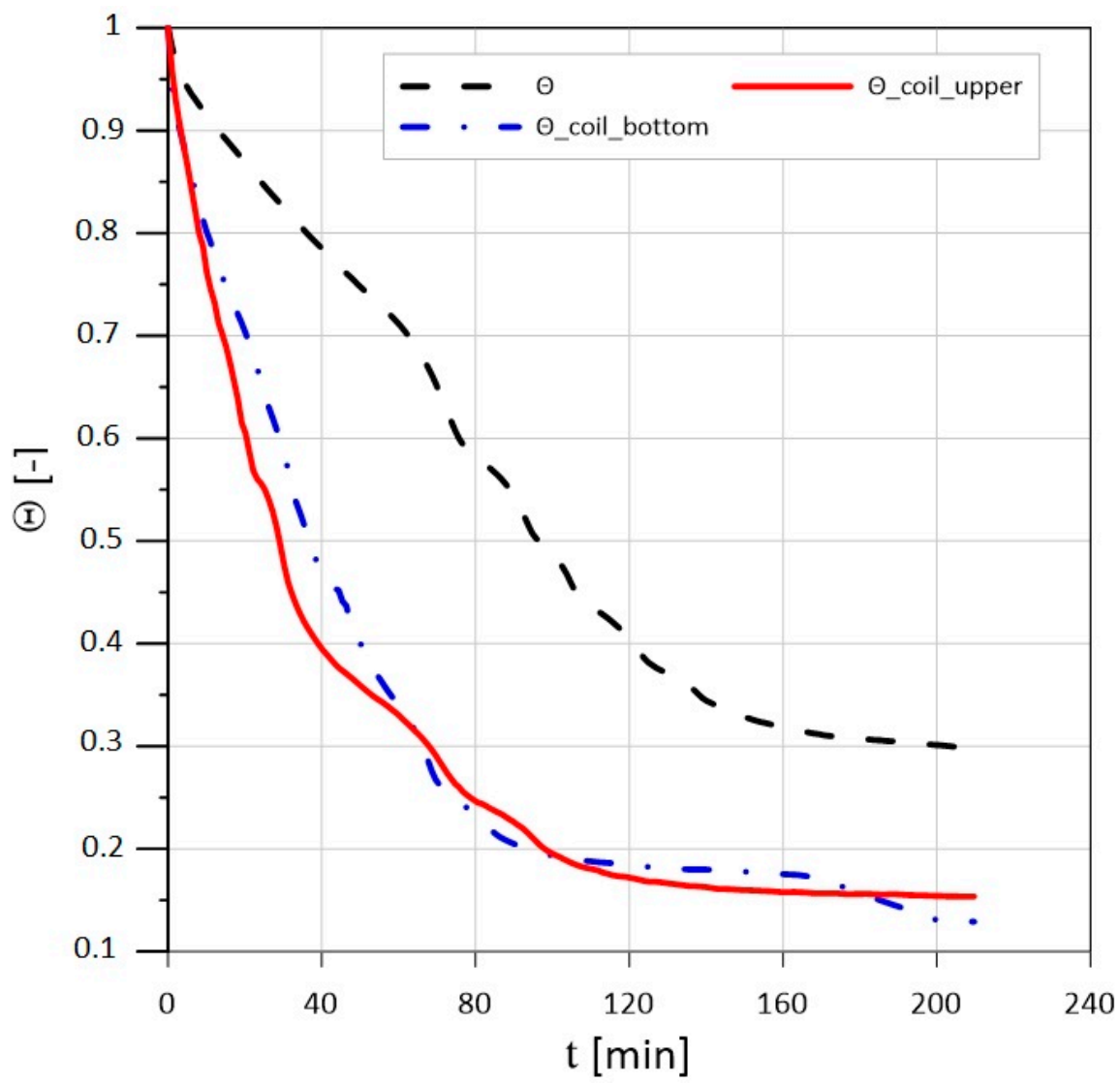

Figure 21. Dimensionless, volume-averaged temperature vs. time during the melting process with a constant wall temperature condition. 


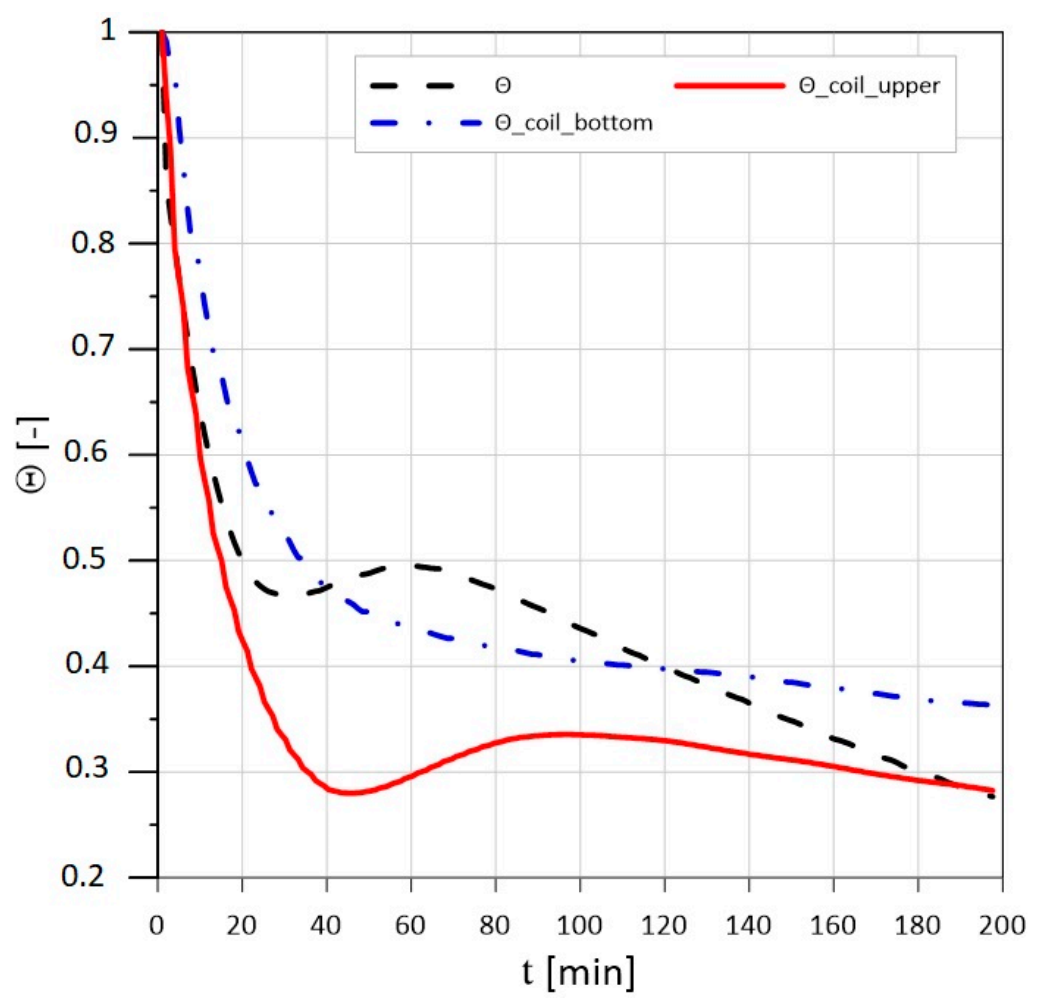

Figure 22. Dimensionless, volume-averaged temperature vs. time during the solidification process with a constant wall temperature condition.

\section{Conclusions}

The authors have chosen natural substance such as coconut oil because of fact that it is easily commercially available and cheap. Which makes it a perspective for use in thermal energy storage systems. The primary objective of the present study was to provide a comprehensive experimental database including multiple temperature profiles in the transition and melting and solidification process for coconut oil since most of the experimental/theoretical studies in the open literature have been concerned with eutectic mixtures or single compound substances.

The significant influence of natural convection on the melting and solidification process has been confirmed. It could be observed that both coil configurations enhanced the melting process compare to the simple annular geometry of TES. However, in the case of the solidification process, the shell-and-coil unit with a coil arranged at the top of the tank has the best performance. The shell-and-coil TES with coil arranged at the bottom region of the tank has comparable performance to the simple annular TES geometry. Therefore it seems that the optimal geometry is a shell-and-coil unit with a coil arranged at the top of the tank.

What is more, the crucial influence of natural convection on solidification phenomena in the case of used asymmetric geometries was confirmed. In the case of annular TES geometry the natural convection effect dominates at the beginning of the phase change process, then it is diminished.

It should be also noted the significant impact of the coil geometrical shape of the heat transfer surface at the shape of the melting/solidification profile.

Author Contributions: Conceptualization, R.A.; methodology, R.A.; validation, R.A. and T.M.; formal analysis, R.A. and T.M.; investigation, P.K.; writing —original draft preparation, R.A. and T.M.; writing—review and editing, R.A. and T.M.; visualization, P.K, R.A. and T.M.; funding acquisition, R.A. All authors have read and agreed to the published version of the manuscript.

Funding: This research work was supported by the National Centre for Research and Development, Poland (Project No. LIDER/4/0008/L-9/17/NCBR/2018). 
Conflicts of Interest: The authors declare no conflict of interest.

\section{Nomenclature}

$\begin{array}{ll}\text { Nomenclature } & \\ \Theta & \text { dimensionless temperature } \\ R & \text { radius } \\ S & \text { surface } \\ T & \text { temperature } \\ V, v & \text { volume } \\ \text { Acronyms } & \\ \text { HVAC } & \text { heat ventilation air conditioning system } \\ \text { LHSS } & \text { latent heat storage system } \\ \text { PCM } & \text { phase change materials } \\ \text { TES } & \text { thermal energy storage } \\ \text { Subscripts } & \\ \text { i } & \text { initial } \\ \text { S } & \text { surface }\end{array}$

\section{References}

1. Kadohiro, Y.; Cheng, S.; Cross, J.S. All-Day Energy Harvesting Power System Utilizing a Thermoelectric Generator with Water-Based Heat Storage. Sustainability 2020, 12, 3659. [CrossRef]

2. Real-Fernández, A.; Navarro-Esbrí, J.; Mota-Babiloni, A.; Barragán-Cervera, Á.; Domenech, L.; Sánchez, F.; Maiorino, A.; Aprea, C. Modeling of a PCM TES Tank Used as an Alternative Heat Sink for a Water Chiller. Analysis of Performance and Energy Savings. Energies 2019, 12, 3652. [CrossRef]

3. Mao, Q.; Liu, N.; Peng, L. Numerical Investigations on Charging/Discharging Performance of a Novel Truncated Cone Thermal Energy Storage Tank on a Concentrated Solar Power System. Int. J. Photoenergy 2019, 2019, 1609234. [CrossRef]

4. Pourakabar, A.; Rabienataj Darzi, A.A. Enhancement of phase change rate of PCM in cylindrical thermal energy storage. Appl. Therm. Eng. 2019, 150, 132-142. [CrossRef]

5. Mahdi, Q.S.; Fattah, L.D.S.A. Experimental and Numerical Investigation to Evaluate the Performance of Helical Coiled Tube Heat Exchanger. J. Eng. Dev. 2014, 18, 89-110.

6. Al-Abidi, A.A.; Mat, S.; Sopian, K.; Sulaiman, M.Y. Internal and external fin heat transfer enhancement technique for latent heat thermal energy storage in triplex tube heat exchangers. Appl. Therm. Eng. 2013, 53, 147-156. [CrossRef]

7. Sun, X.; Zhang, Q.; Medina, M.A.; Lee, K.O. Experimental observations on the heat transfer enhancement caused by natural convection during melting of solid-liquid phase change materials (PCMs). Appl. Energy 2016, 162, 1453-1461. [CrossRef]

8. Zhao, C.; Opolot, M.; Liu, M.; Bruno, F.; Mancin, S.; Hooman, K. Numerical study of melting performance enhancement for PCM in an annular enclosure with internal-external fins and metal foams. Int. J. Heat Mass Transf. 2020, 150, 119348. [CrossRef]

9. Sciacovelli, A.; Gagliardi, F.; Verda, V. Maximization of performance of a PCM latent heat storage system with innovative fins. Appl. Energy 2015, 137, 707-715. [CrossRef]

10. Chen, C.; Zhang, H.; Gao, X.; Xu, T.; Fang, Y.; Zhang, Z. Numerical and experimental investigation on latent thermal energy storage system with spiral coil tube and paraffin/expanded graphite composite PCM. Energy Convers. Manag. 2016, 126, 889-897. [CrossRef]

11. Nitsas, M.; Koronaki, I.P. Thermal Analysis of Pure and Nanoparticle-Enhanced PCM-Application in Concentric Tube Heat Exchanger. Energies 2020, 13, 3841. [CrossRef]

12. Hajizadeh, M.R.; Alsabery, A.I.; Sheremet, M.A.; Kumar, R.; Li, Z.; Bach, Q.-V. Nanoparticle impact on discharging of PCM through a thermal storage involving numerical modeling for heat transfer and irreversibility. Powder Technol. 2020, 376, 424-437. [CrossRef]

13. Hajizadeh, M.R.; Keshteli, A.N.; Bach, Q.-V. Solidification of PCM within a tank with longitudinal-Y shape fins and $\mathrm{CuO}$ nanoparticle. J. Mol. Liq. 2020, 317, 114188. [CrossRef] 
14. Mahdi, M.S.; Mahood, H.B.; Campbell, A.N.; Khadom, A.A. Experimental study on the melting behavior of a phase change material in a conical coil latent heat thermal energy storage unit. Appl. Therm. Eng. 2020, 175, 114684. [CrossRef]

15. Anish, R.; Mariappan, V.; Joybari, M.M.; Abdulateef, A.M. Performance comparison of the thermal behavior of xylitol and erythritol in a double spiral coil latent heat storage system. Therm. Sci. Eng. Prog. 2020, 15, 100441. [CrossRef]

16. Castell, A.; Belusko, M.; Bruno, F.; Cabeza, L.F. Maximisation of heat transfer in a coil in tank PCM cold storage system. Appl. Energy 2011, 88, 4120-4127. [CrossRef]

17. Mousavi Ajarostaghi, S.S.; Poncet, S.; Sedighi, K.; Aghajani Delavar, M. Numerical modeling of the melting process in a shell and coil tube ice storage system for air-conditioning application. Appl. Sci. 2019, 9, 2726. [CrossRef]

18. Mao, Q. Recent developments in geometrical configurations of thermal energy storage for concentrating solar power plant. Renew. Sustain. Energy Rev. 2016, 59, 320-327. [CrossRef]

19. Seddegh, S.; Tehrani, S.S.M.; Wang, X.; Cao, F.; Taylor, R.A. Comparison of heat transfer between cylindrical and conical vertical shell-and-tube latent heat thermal energy storage systems. Appl. Therm. Eng. 2018, 130, 1349-1362. [CrossRef]

20. Zhang, G.; Hu, P.; Liu, M. Thermal performances of non-equidistant helical-coil phase change accumulator for latent heat storage. Sci. China Technol. Sci. 2017, 60, 668-677. [CrossRef]

21. Incropera, F.P.; DeWitt, D.P.; Bergman, T.L.; Lavine, A.S. Fundamentals of Heat and Mass Transfer; John Wiley \& Sons: Hoboken, NJ, USA, 2007.

Publisher's Note: MDPI stays neutral with regard to jurisdictional claims in published maps and institutional affiliations. 